\title{
A REVOLUÇÃO FRANCESA E A EDUCAÇÃO INTEGRAL NO BRASIL: DA CONCEPÇÃO AO CONCEITO
}

\author{
ANTÔNIO CARLOS MACIEL ${ }^{1}$ \\ ORCID: http://orcid.org/0000-0003-0250-4213 \\ ARMINDA RACHEL BOTELHO MOURÃO 2 \\ ORCID: https://orcid.org/0000-0002-1940-9477 \\ CINTIA ADÉLIA DA SILVA ${ }^{3}$ \\ ORCID: https://orcid.org/0000-0002-7455-9814
}

\begin{abstract}
RESUMO: A partir de meados da primeira década dos anos 2000, intensificou-se no Brasil o debate sobre educação integral. Os partidários do "trabalho como princípio educativo" buscaram os fundamentos epistemológicos na concepção marxiana de educação; os diferentes estratos sociais do liberalismo mantiveram-se, no essencial, atrelados à relação entre educação e moral. Uns e outros, contudo, por razões ideológicas, sem explicitar a origem desses fundamentos. Este artigo tem como exato objetivo: demonstrar a origem epistemológica e política da concepção e dos conceitos de educação e de educação integral. Para tanto, utilizou-se da análise histórico-crítica (SAVIANI, 2003; MACIEL e BRAGA, 2008), metodologicamente fundada no materialismo histórico-dialético (MARX, 1983b) para perquirir a trajetória desses conceitos. Em função do método, parte-se da análise dos textos da I Internacional (MARX, 1976; BAKUNIN, 2003) para se chegar a Proudhon (2007) e, daí, por pistas que levam aos textos da Revolução Francesa (CONDORCET, 1792; LEPELLETIER, 1793) que, por sua vez, conduzem a Dewey (1979) e a Teixeira (1959). Como resultado dessa aventura, chega-se às seguintes conclusões: a partir da Revolução Francesa, as concepções de educação fundamentam-se nas dimensões intelectual, física e moral (exceto para Marx); em termos de educação pública, todas levam em consideração a formação para o trabalho, mas as liberais visam ao trabalho subalterno, enquanto que as socialistas, à emancipação. Tal diferença implica em definições antagônicas dos conceitos de educação e de educação integral.
\end{abstract}

Palavras-chave: Revolução francesa; educação integral liberal; educação integral politécnica; concepção; conceito.

\section{THE FRENCH REVOLUTION AND INTEGRAL EDUCATION IN BRAZIL: FROM CONCEPTION TO} CONCEPT

\footnotetext{
${ }^{1}$ Universidade Federal de Rondônia (UNIR). Porto Velho, RO, Brasil.<maciel_ac@hotmail.com>

${ }^{2}$ Universidade Federal do Amazonas (UFAM). Manaus, AM, Brasil. <arachel@uol.com.br>

${ }^{3}$ Universidade Federal do Amazonas (UFAM). Manaus, AM, Brasil. <cintiaadelia.adelia@gmail.com> Educação em Revista|Belo Horizonte|v.36|e236125|2020
} 


\begin{abstract}
Ever since the middle of the first decade of the 2000s, the debate on integral education has been intensified, in Brazil. Those in favor of the "work as an educational principle" have pursued epistemological foundations on a Marxian conception of education; different social sectors of liberalism maintained the same, in its essence, attached to the relation between education and moral. Some individuals, though, based on ideological reasons, without clear explanations of their grounds. This paper aims at demonstrating epistemological and political foundations on the definitions of education and integral education. That was carried out by the use of Historical-Critical Analysis (SAVIANI, 2003; MACIEL e BRAGA, 2008), methodologically based on Dialectical and Historical Materialism (MARX, 1983), to investigate those concepts pathway. Because of the method, we have started from the analysis of I International texts (MARX, 1976; BAKUNIN, 2003) so that we could reach Proudhon (2007) and then set clues that point to the French Revolution (CONDORCET, 1792; LEPELLETIER, 1793), which directs to Dewey (1979) and Teixeira (1959). As a result of this adventure, the following conclusions have been set: from the French Revolution, the concepts on education are grounded on intellectual, physical and moral dimensions (except for Marx); when it comes to public education, all of them take into consideration education for work, nonetheless, liberals focus on subaltern work, whereas socialists focus on emancipation. Such difference implies antagonistic concepts on education and integral education.
\end{abstract}

Keywords: French revolution; liberal integral education; integral polytechnic education; conception; concept.

\title{
LA REVOLUCIÓN FRANCESA Y LA EDUCACIÓN INTEGRAL EN BRASIL: DE LA CONCEPCIÓN AL CONCEPTO
}

RESUMEN: A partir de mediados de la primera década de los años de 2000, el debate sobre la educación integral se intensificó en Brasil. Los partidarios del "trabajo como principio educativo" buscaron fundamentos epistemológicos en la concepción marxista de la educación; los diferentes estratos sociales del liberalismo permanecieron esencialmente vinculados a la relación entre educación y moral. Unos y otros, sin embargo, por razones ideológicas, sin explicar el origen de estos fundamentos. Este artículo tiene como objetivo: demostrar el origen epistemológico y político de la concepción y conceptos de educación y educación integral. Para tanto, utilizamos el análisis histórico-crítica (SAVIANI, 2003; MACIEL y BRAGA, 2008), metodológicamente fundamentado en el materialismo histórico-dialéctico (MARX, 1983b) para investigar la trayectoria de estos conceptos. Debido al método, el análisis comienza con los textos de la I Internacional (MARX, 1976; BAKUNIN, 2003) para llegar a Proudhon (2007) y, de ahí, por pistas que conducen a los textos de la Revolución Francesa (CONDORCET, 1792; LEPELLETIER, 1793) que, a su vez, conducen a Dewey (1979) y Teixeira (1959). Como resultado de esta aventura se llega a las siguientes conclusiones: a partir de la Revolución Francesa, las concepciones de la educación se basan en las dimensiones intelectual, física y moral (excepto Marx); en términos de educación pública, todas llevan en cuenta la formación para el trabajo, pero las liberales apuntan al trabajo subalterno, mientras que las socialistas apuntan a la emancipación. Tal diferencia implica definiciones antagónicas de los conceptos de educación y educación integral.

Palabras clave: Revolución francesa; educación integral liberal; educación integral politécnica; concepción; concepto. 


\section{INTRODUÇÃO}

A concepção de educação integral no Brasil tem sido difundida, basicamente, a partir e por meio da proposta liberal-democrática de Anísio Teixeira. Por outro lado, embora mais recentemente, é crescente a difusão de uma concepção antagônica àquela, por meio de pensadores brasileiros socialistas (marxistas, anarquistas, leninistas, trotskistas), vinculados ao estudo da temática "trabalho e educação". Entre uns e outros, todavia, grassam insuficiências conceituais, que têm gerado confusões de toda ordem, entre as quais, uma que se transformou no objeto deste artigo: a origem da concepção de educação integral.

Do lado socialista, a proposta marxiana é amplamente hegemônica, mas tal proposta era exclusiva ou era comum a outros militantes da Associação Internacional dos Trabalhadores - AIT, em particular, a Bakunin e a Robin? E antes da AIT (mundialmente conhecida como Primeira Internacional) qual papel coube a Proudhon na formulação desta concepção?

Do lado liberal, se Anísio Teixeira é herdeiro da concepção educacional de Dewey, em que consiste essa herança? E mais: na medida em que Dewey é um renovador do pensamento educacional liberal, como se vincula aos ideais da Revolução Francesa, em particular, aos Planos de Condorcet e de Lepelletier?

Pensa-se que a demonstração dessas conexões pode explicar as origens da concepção e, por conseguinte, do conceito de educação integral, que serviram de fundamento epistemológico às grandes vertentes brasileiras: de um lado a liberal escolanovista e, de outro, a marxista.

Autores outros, porém, têm buscado essa origem em tempos mais longínquos: Gadotti (2009, p. 21) a identifica em Aristóteles, mas como já se teve a oportunidade de assinalar: a condição da natureza humana na sociedade escravista não permite associá-la à condição humana na sociedade de classe (MACIEL, 2019). Tanto Locke, quanto Rousseau têm influência direta na concepção de educação da Revolução Francesa. Ambos a concebem à base de princípios que, a despeito da diferença terminológica, significam relativamente a mesma coisa: o primeiro, por meio das dimensões física, moral e intelectual (OLIVEIRA; SILVA, 2018); o segundo, por meio da educação natural, para fortalecimento do corpo e refinamento dos sentidos, e da educação pública, para a formação moral, jurídica e política (DALBOSCO, 2012), ainda que tais princípios estejam resguardados para os privilegiados e não para os despossuídos, tal como propõe Locke, por meio das working-schools (TAMBARA; ARRIADA, 2017) e Rousseau para quem a educação do "homem civil" decorre do direito de propriedade (ROUSSEAU, 1762, Livro I, VIII-XIX).

Mas as vertentes brasileiras, tratadas aqui, não se nutrem dessas fontes, e sim dos Planos Educacionais da Revolução Francesa, do mesmo modo como não são influenciadas por autores contemporâneos à Primeira Internacional, tais quais Spencer, cujos princípios são os mesmos da Revolução Francesa (SPENCER, 1860) e Tolstoi, cuja obra, ainda hoje, tem pouquíssima penetração, mesmo no pensamento educacional anarquista brasileiro (SANTOS, 2014), muito menos em autores mais recentes, por exemplo, Alexander Neill (1970) e Janusz Korczak (BARRERA, 2016). Estes dois últimos, aliás, em termos de influência na educação brasileira, não chegam nem perto da influência exercida por Montessori, haja vista a quantidade de Casas da Criança que havia, e ainda há no Brasil (OMB, 2020).

Não é outra a razão pela qual circunscreve-se, aqui, as origens da concepção de educação integral aos Planos da Revolução Francesa e aos debates educacionais da Primeira Internacional, na qual o termo fora ratificado para distinguir a educação a que as classes trabalhadoras deveriam almejar, daquela - reduzida às primeiras letras e às necessidades básicas do mundo do trabalho - destinada a elas pelo Estado burguês.

Para tanto, fez-se uso da análise histórico-crítica (SAVIANI, 2003; MACIEL e BRAGA, 2008), que se fundamenta no método histórico-dialético (MARX, 1980, p. 13-17; 1983b, p. 24-25, 218223; NETTO, 2011), por meio dos quais comparam-se os fundamentos epistemológicos dos autores, na busca por unidade, diferenças e antagonismos, motivo pelo qual o tema não é abordado cronologicamente, pelo contrário, busca-se o fundamento de uma afirmação de Marx, na sessão do dia 17 de agosto de 1869, no Conselho Geral da AIT, na legislação educacional da Revolução Francesa e, a 
partir desta, os vínculos epistemológicos com Anísio Teixeira, o introdutor da educação integral no Brasil. Com isso, pensa-se alcançar o emprego do método de exposição da teoria na análise do tema.

Espera-se que a trajetória percorrida permita perceber que a concepção educacional da Primeira Internacional é uma antítese à concepção educacional liberal da Revolução Francesa, e é esta condição, cuja totalidade engendra unidade e diversidade das concepções teóricas, que possibilita apreender as contradições decorrentes de seus compromissos de classe.

Nas sociedades de classe, onde a história das sociedades nada mais é do que a história da luta de classes, a educação, em sentido amplo, sempre esteve restrita às classes dominantes, quer sejam aristocratas, nobres, clero ou burguesa; às classes dominadas, quer sejam escravos, servos, camponeses ou trabalhadores assalariados (MARX; ENGELS, 1998, p. 40-41), quando muito, cabia-lhes o ensino das primeiras letras.

Nas modernas sociedades de classe, mesmo com as conquistas da Revolução Francesa (1789), a educação foi estratificada de acordo com as necessidades sociais do desenvolvimento da sociedade capitalista. Assim, o Estado burguês criou um sistema público-estatal destinado ao atendimento das necessidades básicas da sociedade (extensivo a vários setores intermediários, tanto do mundo do trabalho direto, quanto do mundo burocrático) e um sistema privado, hierarquicamente distribuído, conforme o poder econômico das classes médias superiores e das diversas classes burguesas (MACIEL, 2013, p. 76-79, 93-100).

As organizações operárias que, no século XIX, lutavam contra a exploração capitalista e a miséria em que as classes trabalhadoras - operários, artesãos e camponeses - se encontravam, logo perceberam que, a luta sindical por melhores condições de trabalho, estava associada à luta por melhores condições de vida, entre as mais importantes, moradia, alimentação e ensino estatal desvinculado da igreja e que, portanto, tratava-se de uma luta política (ENGELS, 2008; THOMPSON, 2004; HOBSBAWN, 1982). Neste último caso, a Associação Internacional dos Trabalhadores, criada em 1864, colocou em pauta, desde os primeiros momentos organizativos, a luta por um tipo de educação, que colocasse os trabalhadores em igualdade de condições educacionais para lutar por seus interesses políticos, tal como proclama Bakunin (2003, p. 69): “[...] queremos a igualdade, e porque a queremos, devemos querer também a instrução integral, igual para todos".

No Primeiro Congresso Internacional dos Trabalhadores da Primeira Internacional, em 1866, surgia, então, a concepção proletária de educação, o gérmen da concepção proletária de educação integral.

\section{A CONCEPÇÃO PROLETÁRIA DE EDUCAÇÃO NA PRIMEIRA INTERNACIONAL: ORIGEM DA CONCEPÇÃO PROLETÁRIA DE EDUCAÇÃO INTEGRAL}

A mais difundida concepção proletária de educação no Brasil, que remonta ao Primeiro Congresso Internacional dos Trabalhadores, ocorrido em Genebra, em 1866, encontra-se nas "Instruções aos Delegados do Conselho Central Provisório", documento escrito por Marx (1976, p. 179), segundo quem:

Par éducation, nous entendons trois choses: 1. éducation intellectuelle; 2. éducation corporelle, telle qu'elle est produite par les exercices gymnastiques et militaires; 3. éducation technologique, embrassant les principes généraux et scientifiques de tous les procès de production, et en même temps initiant les enfants et les adolescents au maniement des instruments élémentaires de toutes les branches d'industrie ${ }^{4}$.

A concepção marxiana, portanto, abrange três dimensões: a intelectual, a corporal, enquanto educação física e militar, e a educação tecnológica, chamada também de politécnica, por ele próprio (1976, p. 179):

À la division des enfants et des adolescents en trois catégories, de 9 à 18 ans, doit correspondre un cours gradué et progressif pour leur éducation intellectuelle, corporelle et polytechnique.

\footnotetext{
${ }^{4}$ Optou-se pela versão francesa, por estar coerente com a tradução brasileira mais conhecida (MARX, 1983a, p. 60). A versão inglesa (1996, p. 6), traduz a expressão "éducation technologique" como "technological training", mas não deixa de alertar: "The German text calls this "polytechnical training". 
[...] Cette combinaison du travail productif, payé avec l'éducation intellectuelle, les exercices corporels et la formation polytechnique, élèvera la classe ouvrière [...].

Para a concepção marxiana de educação, a pedra angular é a educação tecnológica ou politécnica que, ao tratar dos princípios gerais do processo produtivo associado à formação intelectual e corporal, proporcionaria ao educando as condições necessárias para superar a formação das classes burguesas e aristocráticas (MARX, 1983a, p. 60). Ora, o processo segundo o qual será possível superar a formação das classes burguesas não pode ser senão pela via da organização política das classes trabalhadoras, de que a própria Associação Internacional é a ação mais acabada e o gérmen da organização política dos trabalhadores em todo o mundo, tal como já fora proclamada em 1848 (MARX; ENGELS, 1998) e ratificada em 1875 (MARX, 1979), na Crítica ao Programa de Gotha.

Esse postulado, todavia, era comum à vanguarda do Movimento Operário da Associação Internacional dos Trabalhadores, de tal sorte que pode ser facilmente encontrado em Bakunin, em Robin e, antes destes, em Proudhon. Bakunin (2003, p.78 e 81), em 1869, ao publicar a Instrução Integral, assevera:

A instrução deve ser igual em todos os graus para todos; por conseguinte, deve ser integral, quer dizer, deve preparar as crianças de ambos os sexos tanto para a vida intelectual como a vida do trabalho, visando a que todos possam chegar a ser pessoas completas [...] Na instrução integral, ao lado do ensino científico ou teórico, deve haver necessariamente o ensino industrial ou prático. Só assim se forma o homem completo: o trabalhador que compreende e sabe.

Fica evidente, desde logo, duas dimensões: a intelectual e o trabalho, no entanto, não se pode deixar de observar que a "instrução deve ser igual em todos os graus para todos", portanto, sem distinção de classe e, mais que isso, sem distinção de gênero, uma vez que, para ele, a instrução integral "deve preparar as crianças de ambos os sexos". Se Bakunin, todavia, não é enfático quanto à formação física, o é dissimuladamente, quando enfatiza que a moral é a base da igualdade e para alcançá-la é necessário a força física dos homens, já que estes são produto da "ação combinada da natureza e da sociedade" e que "para moralizar os seres humanos, é necessário moralizar o meio social, para o que só há um meio: "fazer triunfar a justiça" (BAKUNIN, 2003, p. 90). Assim, para Bakunin, a Moral (não religiosa, como deixa bem claro, p. 82-90) é uma dimensão de primeira ordem, porquanto moral revolucionária.

Robin (1837-1912), bem mais novo que Bakunin (1814-1876) e Marx (1818-1883), participa do Primeiro Congresso da Associação Internacional dos Trabalhadores, mas é a partir do Segundo e do Terceiro, que se sobressai. A concepção de educação integral para Robin apud Violet (2002, p. 24) pode ser constatada, quando afirma:

Nous n'avons pas le moins du monde la prétention de faire de nos élèves des savants universels. Par ce mot d'éducation intégrale, nous entendons celle qui tend au développement progressif et bien équilibré de l'être tout entier, sans lacunes, ni mutilation, sans qu'aucun côté de la nature humaine soit négligé ni systématiquement sacrifié à un autre. [...]L'éducation intégrale contient et réunit les trois facteurs habituels, à savoir : l'éducation physique, intellectuelle et morale ${ }^{5}$.

Certamente, as dimensões física e intelectual são coincidentes; a associação ao trabalho fica mais evidente em outras passagens, nesta, todavia, a menção à mutilação causada pela divisão do trabalho confirma tal compreensão. Mas não se pode deixar de assinalar a ênfase dada à moral, nesse momento, não só porquanto seja uma vinculação à Proudhon e Bakunin (e, portanto, a ênfase que a concepção anarquista dá à educação moral), mas também pelo fato de que o Robin, mais maduro, progressivamente, substitui o termo "moral" pelo "afetivo", particularmente, após a experiência pedagógica no Orfanato Prévost, em Cempuis (ROBIN, 1902). A experiência de Cempuis parece afastá-lo da concepção anarquista da Primeira Internacional e aproximá-lo de uma das concepções escolanovistas, a de natureza assistencialista, muito em voga na Europa da virada do século XIX para o século XX (SAVIANI, 2005).

Ainda quanto a Robin, não se pode deixar de assinalar, que um dos objetivos da educação, decorre do pressuposto, comum na Internacional, dos males causados ao homem pela divisão do

\footnotetext{
${ }^{5}$ Renaud Violet (2002, p. 34), por sua vez, retira a citação do livro de Roland Lewin, intitulado Sébastien Feure et la Ruche. Tal concepção é confirmada por Husson (1949, p. 9, 13, 21), que mostra, também, a indissociável relação com o trabalho produtivo (HUSSON, 1949, p. 10, 21). 
trabalho. Não à toa, diz "entendemos por educação integral que o tende ao desenvolvimento progressivo e bem equilibrado do ser como um todo, sem lacuna, nem mutilação" (VIOLET, 2002, p. 24), e ipsu facto “[...] étant entendu qu'elle doit avoir pour base «des réalités objectives» et «la vérité scientifique» et pour objectifs «toutes les branches de l'activité humaine»" (VIOLET, 2010, p. 23). Ora, "todos os ramos da atividade humana" é uma transcrição quase literal de "[...] et en même temps initiant les enfants et les adolescents au maniement des instruments élémentaires de toutes les branches d'industrie" (MARX, 1976, p. 179).

Nesse sentido, pode-se afirmar que a concepção de formação para o trabalho de Robin se aproxima da de Marx. Não sem razão, sobre a resolução educacional, elaborada por Robin ao Terceiro Congresso da Internacional, em 1968, Robin teria dito: “[...] une résolution «conforme à ses voeux et à ceux de Marx»" "VIOLET, 2010, p. 22).

Os fundamentos educacionais, alicerçados na instrução intelectual, na instrução para o trabalho, na moral, não religiosa e que tem por base a força física (Bakunin), ou na educação física, intelectual e moral (Robin), porém, quando não são a expressão, são a interpretação atualizada dos fundamentos educacionais de Proudhon. De acordo com este (2007, p. 307):

[...] o problema da divisão do trabalho não consiste somente em realizar a maior quantidade de produtos; consiste também em realizar essa quantidade sem prejuízo físico, moral ou intelectual para o trabalhador. Ora, está provado que a inteligência do trabalhador está tanto mais inclinada à idiotice quanto mais o trabalho é dividido ${ }^{7}$; e reciprocamente, quanto mais o homem abrange coisas em suas combinações, transferindo a outros os desgostos da execução e o cuidado dos detalhes, tanto mais sua razão se fortalece, mais seu gênio se eleva e domina. Como, pois, conciliar a necessidade de uma divisão parcelar com o desenvolvimento integral das faculdades, desenvolvimento que para cada cidadão é um direito e um dever, e para todos uma condição de igualdade?

Observe-se que as dimensões física, moral e intelectual do trabalhador se encontram na base das preocupações acerca da formação humana. Formação essa que é mutilada pela divisão parcelar do trabalho, cujo processo idiotiza o trabalhador; por outro lado, a formação abrangente, que prioriza as combinações (trabalho manual e intelectual e as diferentes combinações das atividades laboriosas) fortalece a razão e o gênio. A perspectiva proudhoniana propõe a superação da divisão do trabalho, mas "[...] sem proibir a iniciativa individual [...] assegure a igualdade política e industrial dos cidadãos e, por um vasto sistema de educação pública, proporcione [...] a igualdade das funções e a equivalência das aptidões [...]" (PROUDHON, 2007, p. 426). Assim, uma educação não idiotizante é aquela que concilia divisão parcelar com desenvolvimento integral das faculdades humanas, condição da igualdade.

Tal conciliação, condição da igualdade, pela via da combinação entre o manual e o intelectual é reforçada, quando Proudhon (2003, p. 221) sustenta:

\begin{abstract}
Se a educação fosse antes de mais nada experimental e prática, reservando os discursos apenas para explicar, resumir e coordenar o trabalho; se fosse permitido aprender pelos olhos e pelas mãos aquilo que não se pode aprender pela imaginação e pela memória, logo veríamos com as formas do trabalho, multiplicarem-se as capacidades; todos, conhecendo a teoria de alguma coisa, saberiam por isso mesmo a língua filosófica e poderia acontecer, ao menos uma vez na vida, que alguém pudesse criar, modificar, aperfeiçoar, dar provas de inteligência e de compreensão, produzir sua obra-prima, ou seja em uma palavra, mostrar-se homem. A desigualdade das aquisições da memória em nada modificaria a equivalência das faculdades e o gênio não nos pareceria mais do que é com efeito: a saúde do espírito.
\end{abstract}

Claro está que a concepção de educação de Proudhon tem por fundamento as deformações causadas ao trabalhador, pela divisão parcelar do trabalho. Por isso, a educação desse homem não pode

\footnotetext{
${ }^{6}$ Essa aproximação conceptual, também, é confirmada por Husson (1949, p. 21): “Comme on le voit Robin recherchait une éducation morale basée sur le travail ouvrier et il s'efforçait aussi d'y rattacher l'éducation intellectuelle. Comme le voulait Proudhon, il demandait qu'on le fasse naitre de la pratique des métiers, de la réflexion sur les différents arts et de la compréhension des techniques".

${ }^{7}$ No mesmo sentido Marx (1980, p. 416), após longa análise sobre as deformações físicas e espirituais causadas pela divisão técnica do trabalho, sentencia: "Subdividir um homem é executá-lo, se merece a pena de morte; e se não a merece, assassinálo... A subdivisão do trabalho é o assassinato de um povo".

Educação em Revista|Belo Horizonte|v.36|e236125|2020
} 
ser apenas experimental, prática; deverá sê-lo, também, intelectual, para que possa criar, modificar, aperfeiçoar, dar provas de inteligência e compreensão. Tal educação não poderá ser levada a efeito senão por uma escola, que vise ao desenvolvimento físico, intelectual e moral. Portanto, sem desconsiderar as diferenças pontuais, Proudhon, Bakunin e Robin defendem os mesmos princípios educacionais.

Cabe, por fim, assinalar a reivindicação da natureza laica da educação em detrimento da educação religiosa, principalmente, quando defendidas por socialistas. A posição de Proudhon (2007, p. 276-279) acerca da igreja e sua educação vem sob a forma de crítica ao que ele denomina de "comunistas do socialismo utópico", em particular a Etienne Cabet, por defender a fraternidade como princípio social, e da qual não escapam Charles Fourier, por pregar a ideia de que "era necessário agrupar as pessoas em falanstérios, espécie de cooperativas de produção e de consumo, cujos rendimentos deveriam ser repartidos entre o trabalho, o talento e o capital" (SILVA e MIORANZA, 2007, p. 266); a Jules Michelet, por sustentar o amor e o instinto como princípio de vida e a Louis Blanc por defender "[...] a grande força de iniciativa do Estado, sinônimo da onipotência de Deus” (PROUDHON, 2007, p. 281).

Em síntese, Proudhon não participa da Primeira Internacional dos Trabalhadores, morrera um ano antes, porém, se vivo estivesse, difícil deduzir se participaria, dada a suposta indiferença a Marx (MOREL, 2003, p. 12-32) ou aos possíveis embates, que poderiam ocorrer, em função da ácida polêmica entre os dois.

Fato é que, pensa-se, está demonstrado que os princípios educacionais, vigentes na Associação Internacional dos Trabalhadores, propostos por Marx, Bakunin, Robin (em todos os casos com indisfarçável contribuição de Proudhon) são princípios que se apoiam em três dimensões: educação intelectual, educação física e educação pelo trabalho. Esta última recebe diferentes denominações: tecnológica ou politécnica, Marx; instrução profissional, Bakunin; politécnica, Robin; trabalho individual e coletivo, Proudhon.

A grande diferença, que com um olhar mais a miúde não é tão grande assim, reside na quarta dimensão: para Proudhon como para Bakunin e Robin, essa dimensão é constituída pela educação moral; para Marx, embora não esteja explicitamente formulada, esta dimensão é constituída pela formação política, via que, por assim dizer, levaria as classes trabalhadoras a superar a organização burguesa. Ocorre, todavia, que, tanto para Proudhon como para Bakunin e Robin, a educação moral, não deve se constituir apenas de uma ética identitária das classes trabalhadoras, mas de uma ética contrária à da burguesia, aos princípios basilares de sua sociedade, em particular, a propriedade e, fundamentalmente, uma ética contrária ao seu Estado, logo uma moral constituída de princípios e formação política. O Quadro I é uma tentativa didática de sintetizar as dimensões pedagógicas da concepção educacional desses autores:

\section{Quadro I - Síntese das dimensões pedagógicas da concepção educacional da Associação Internacional dos Trabalhadores}

\begin{tabular}{|l|l|l|l|l|}
\hline \multicolumn{1}{|c|}{ Autor } & \multicolumn{4}{|c|}{ Dimensões pedagógicas da concepção educacional } \\
\hline Marx & Educação intelectual & $\begin{array}{l}\text { Educação física } \\
\text { e militar }\end{array}$ & $\begin{array}{l}\text { Educação tecnológica ou } \\
\text { politécnica }\end{array}$ & $\begin{array}{l}\text { Educação } \\
\text { política }\end{array}$ \\
\hline Proudhon & Educação intelectual & Educação física & Trabalho individual e coletivo & Moral \\
\hline Bakunin & Instrução intelectual & Força física & Instrução profissional & Moral \\
\hline Robin & Educação intelectual & Educação física & Educação politécnica & Moral \\
\hline
\end{tabular}

Fonte: Elaborado pelos autores.

O objetivo, aqui, era o de mostrar que o pensamento educacional da Associação Internacional de Trabalhadores era comum, mesmo entre duas posições políticas, que se digladiavam sobre diversos temas e que, nesta Associação, reside a origem da concepção proletária de educação integral.

Agora, passa-se a ver como esse pensamento se vincula, em grande parte, à concepção burguesa de educação. Segue-se, aqui, uma pista deixada por Marx, na defesa que faz de sua concepção educacional, em 1869, no Conselho Geral da AIT, diz ele (1983a, p. 98): "Neste ponto, partiu-se sempre do que a burguesia entente por formação politécnica, o que produziu interpretações errôneas". 
Portanto, com o propósito de demonstrar essa vinculação, foi-se direto aos Planos Educacionais da Revolução Francesa, arquivados naBiblioteca da Assembleia Nacional Francesa.

\section{A CONCEPÇÃO BURGUESA DE EDUCAÇÃO: ORIGEM DA CONCEPÇÃO BURGUESA DE EDUCAÇÃO INTEGRAL}

A maioria dos autores brasileiros que tratam da temática, como é possível conferir em Maciel, Jacomeli e Brasileiro (2017), ao criticar a escola burguesa, esquece de que o pensamento educacional da burguesia revolucionária dá origem ao pensamento educacional revolucionário da AIT, e de que este o supera pela crítica (e, na Comuna de Paris, pela prática); de que, mesmo no apogeu da Revolução Francesa, a educação pública foi pensada para diferenciar as classes sociais; de que a proposição de igualdade entre os homens fora uma formalidade necessária para acalmar os ânimos exacerbados durante o processo revolucionário.

Logo, mesmo no âmbito do público-estatal da Revolução Francesa, a concepção de educação será, a seu tempo única, variando, porém, no acesso (restrito à escola primária para as classes pobres do campo e da cidade) e nas condições infraestruturais (físicas e pedagógicas) da escola. Por estas e outras razões, os Planos Educacionais de 1792, de Condorcet, e 1793, de Lepelletier, não foram postos em prática: o dito e proclamado ficou no papel!

\section{A concepção burguesa de educação no tempo da Revolução Francesa: dito e não feito!}

O Plano Educacional de Condorcet intitulado "Rapport et projet de décret sur l'organisation générale de l'instruction publique", apresentado "à l'Assemblée Nationale au nom du Comité de Instruction Publique", nos dias 20 e 21 de abril de 1792, é um marco do pensamento revolucionário da época, e mesmo assim não logrou aprovação pela Assembleia Nacional.

O Plano não deixa dúvidas quanto à concepção educacional, a partir de dois objetivos fundamentais: a igualdade (de fato) entre os homens e a educação constituída pela formação física (na qual estão incluídas as habilidades para o trabalho), intelectual e moral.

Logo nos fundamentos, Condorcet (1972, p. 2) é enfático quanto ao direito do cidadão à educação: “[...] établir entre les citoyens une égalité de fait, et rendre réelle l'égalité politique reconnue par la loi. Tel doit être le premier but d'une instruction nationale". Portanto, a igualdade política reconhecida por lei nada mais é do que a igualdade formal, que deveria ser realizada, mas não o foi.

Especificamente, a igualdade reconhecida por lei teria por base a concepção de que o Estado deveria "Assurer, à chacun d'eux, la facilité de perfectionner son industrie, de se rendre capable des fonctions sociales auxquelles il a droit d'être appelé, de développer toute l'étendue des talents qu'il a reçus de la nature [...]“ (CONDORCET, 1792, p. 2). Logo, o aperfeiçoamento dos fazeres industriais, das capacidades para as funções sociais e do desenvolvimento dos talentos humanos são, assim, sintetizados: "Cultiver enfin, dans chaque génération, les facultés physiques, intellectuelles et morales [...]. Tel doit être encore l'objet de l'instruction; [...]" (CONDORCET, 1792, p. 2). Portanto, esse é o objetivo especificamente educacional e a afirmação de que o trabalho se inclui no âmbito da formação física, pode ser medida pela passagem onde Condorcet (1792, p. 9) afirma: "La gymnastique ne sera point oubliée; mais on aura soin d'en diriger les exercices de manière à développer toutes les forces avec égalité, à détruire les effets des habitudes forcées que donnent les diverses de travaux".

Implicitamente, o que fica claro, a partir disso, porém, é a hierarquização dos graus de ensino, aos mais elevados dos quais somente as classes, que poderiam custear, poderiam ter acesso. Nesse sentido, Condorcet (1972, p. 5) distingue cinco graus de instrução por cinco tipos de escolas: Primárias, Secundárias, Institutos, Liceus e Sociedade Nacional de Ciências e Artes. Com aritmética triagem, os "pobres" do campo e da cidade poderiam chegar às escolas secundárias. Mas como se sabe, isso ficou no dito.

O Plano Educacional de Lepelletier, intitulado "Plan d'Éducation Nationale", apresentado "a la Convention par Maximilen Robespierre, au nom de la Comission d'Instruction Publique", no dia 13 de julho de 1793, após o assassinato de seu autor, é o outro marco fundamental do pensamento revolucionário burguês, em termos educacionais. O Plano está estruturado em cinco partes: a "Éducation 
Nationale", os "Articles Généroux", os "Articles de l'Éducation Nationale", os "livres Élèmentaires a Composer" e as "Questions a Resoudre". Corroborando, em grande parte com Condorcet, Lepelletier (1793, p. 15) é direto:

Donner à tous les habitudes physiques et les habitudes morales, les instructions et les connaissances qui, étant acquises dans l'enfance, influent sur tout le reste de la vie, qu'il importe à tous d'acquérir, qui ont une commune utilité pour tous, à quelque profession qu'ils le destinent, et qui doivent produire une masse sensible d'avantages pour la société, lorsqu'elle en aura également pourvu tous les membres qui sont destinés à la composer.

A semelhança da concepção de Lepelletier com a concepção de Condorcet salta aos olhos de imediato. Porém, Lepelletier é explícito: a educação intelectual se divide em instrução e conhecimento, distinguindo, na educação nacional, o conhecimento, destinado aos graus posteriores aos 12 anos, da instrução pública e gratuita até os 12 anos, conforme se pode conferir no Plano (p. 3-4):

Tout le système du comité porte sur cette base, l'établissement de quatre degrés d'enseignement; savoir, les écoles primaires, les écoles secondaires, les instituts, les lycées. Je trouve dans ces trois derniers cours un plan qui me paraît sagement conçu pour la conservation, la propagation et le perfectionnement des connaissances humaines. Ces trois degrés successifs ouvrent à l'instruction une source féconde et habilement ménagée, et j'y vois des moyens tout à la fois convenables et efficaces pour seconder les talents des citoyens qui se livreront à la culture des lettres, des sciences et des beaux-arts.

Além disso, como é objetivamente assinalado em diversas passagens do Plano de Lepelletier, a instrução envolve o trabalho manual (diferentemente de Concordet, que inclui na educação física) necessário às diversas profissões da sociedade: "L'enfant est parvenu à douze ans; a cet áge finit pour lui l'instituition publique: il le temps de le rendre aux divers travaux de l'industrie" (p. 37), ou, ainda, no décimo artigo da educação nacional: "Durant le cours de l'éducation nationale, le temps de enfants sera partagé entre l'étude, le travail des mains, \& leur exercices de la gymnastique” (p. 44).

Não à toa, Marx afirmara que sua concepção de educação partia da concepção burguesa (em seu momento revolucionário, diga-se de passagem), no exato entendimento de que se constitui de estudo (educação intelectual), trabalho manual (educação tecnológica ou politécnica) e exercícios físicos (educação corporal). A grande diferença, todavia, reside no fato de que, mesmo para a burguesia revolucionária, a educação para o trabalho visa, conforme ainda o quarto artigo geral do Plano de Lepelletier (p. 39): "L'objet de l'éducation nationale sera de fortifier le corps des enfants, de le développer par des exercices de gymnastique, de les accoutumer au travail des mains, de les endurcir à toute espèce de fatigue, de les plier au joug d'une discipline salutaire [...]".

Enquanto que para Marx, trata-se de superar a divisão técnica e social do trabalho e, portanto, condição sine qua non para a superação do processo de alienação e meio sem o qual a emancipação se torna impossível; para Lepelletier, trata-se exatamente do contrário: de manter a divisão técnica e, por conseguinte, a divisão social do trabalho e, portanto, de manter a estrutura da sociedade dividida por classes sociais ${ }^{8}$.

Em todo o caso, o Plano de Lepelletier, embora aprovado, jamais foi posto em prática, sendo, portanto, outro Plano dito e não feito!

Mesmo assim, na concepção burguesa de educação, expressa pelo momento supremo da Revolução Francesa, se encontram as origens da concepção proletária de educação e, por conseguinte, as concepções de educação integral de ambas as classes.

Pelo lado burguês, as concepções de educação e de educação integral somente podem ser entendidas no contexto histórico da divisão social do trabalho capitalista, do qual Dewey é a expressão mais acabada e, pela grande influência que vai exercer na educação brasileira, por meio de Anísio Teixeira, é um nome primordial para a compreensão desse contexto.

\footnotetext{
${ }^{8}$ No Plano de Lepelletier reside a origem da divisão do sistema educacional em duas redes de ensino. Tanto Snyders (2005), quanto Saviani (2008) analisando "A Escola Capitalista na França", de Baudelot e Establet, chegam à conclusão de que a divisão dos sistemas escolares reproduz a divisão social, mas, ao contrário de Baudelot e Establet, não a entendem como via de mão única, e sim como expressão da luta de classes.
}

Educação em Revista|Belo Horizonte|v.36|e236125|2020 


\section{A concepção burguesa de educação em Dewey: desenvolvimento natural, eficiência social e cultura: dito e não aceito!}

As propostas educacionais da burguesia revolucionária não saíram do papel, daí o "dito e não feito". No decurso do século XIX, tais formulações retroagem ao pensamento mais conservador do liberalismo e à convivência pacífica com o ensino religioso da Igreja, quer seja católica ou protestante. E é nesse contexto, que se deve entender tanto a concepção educacional crítica da Associação Internacional dos Trabalhadores (já exposta), cujo paroxismo se dá na Comuna de Paris, quanto a liberal-democrática de John Dewey.

Com efeito, pode-se afirmar que a concepção educacional de Dewey é uma continuidade aprofundada, política e epistemologicamente, da concepção educacional da Revolução Francesa para a escola pública. Politicamente, porque não limita a obrigatoriedade aos doze anos de idade; epistemologicamente, por aproveitar os avanços e as contribuições de diversos campos da ciência, entre os quais da biologia, das ciências sociais e da psicologia.

Do ponto de vista epistemológico, a concepção educacional de Dewey parte do estágio alcançado pelo conhecimento científico da época: ao reconhecer que as "[...] atividades naturais significam atividades inatas que se desenvolvem unicamente por meio dos usos com os quais são aperfeiçoadas" (1979, p. 134). Numa palavra: o ser humano como síntese biológica e cultural constitui a primeira dimensão da concepção deweyana de educação.

Tal reconhecimento do desenvolvimento natural não entra em choque com o fundamento rousseauniano acerca da natureza humana (SBRANA, 2018, p. 143-156), base da concepção educacional revolucionária de 1792-1793, porém, seu desenvolvimento não é mais espontâneo, como em Rousseau, mas decorrente dos usos com os quais é aperfeiçoado, o que está de comum acordo com as contribuições do darwinismo, de um lado e, de outro, com a própria contribuição de Rousseau adotada por Dewey, ao visar à "saúde e a robustez do corpo", o respeito à "mobilidade física" e à consideração às "diferenças individuais" (DEWEY, 1979, p. 125-126).

Nesse sentido, “[...] a função da educação é fornecer precisamente aquilo que a natureza deixa de proporcionar, isto é, fazer o indivíduo habituar-se à influência social e subordinar as faculdades inatas às regras sociais" (DEWEY, 1979, p. 129). Ora, o desenvolvimento das faculdades nada mais é do que "eficiência" e a eficiência social se consegue pelo "uso positivo das faculdades individuais inatas, em ocupações que tenham significação social” (DEWEY, 1979, p. 129).

Com base nessa compreensão e, então, passa-se do plano epistemológico para o político, para Dewey (1979, p. 134): “[...] a tarefa especial da educação nos tempos atuais é lutar em prol de uma finalidade em que a eficiência social e a cultura pessoal sejam coisas idênticas e, não, antagônicas”. Por eficiência social, a segunda dimensão da concepção, Dewey entende duas coisas: eficiência industrial (econômica) e eficiência cívica (o bom cidadão).

A eficiência industrial ou econômica é a base da prosperidade individual que, por sua vez, é o alicerce do progresso social, ou como o próprio acentua "[...] o progresso de um de seus membros tem valor para a experiência dos outros membros" (DEWEY, 1979, p. 89) ${ }^{9}$. Porém, tal prosperidade depende, para ele, Dewey (1979, p. 91), da:

\section{[...] eficiência da produção (que) exige com frequência a divisão do trabalho. Mas este se reduzirá a uma rotina maquinal se o trabalhador não vir as relações técnicas, intelectuais e sociais encerradas naquilo que está fazendo, em relação às demais partes do trabalho, e não se dedicar a seu trabalho por essa compreensão.}

O fato de acentuar que a divisão do trabalho não deve se reduzir a uma rotina mecânica, na qual as funções técnicas, intelectuais e sociais estejam dissociadas, parece levar à conclusão de que essa crítica à "organização científica do trabalho" (p. 91), que também é uma crítica aos "que dirigem à indústria" (ainda p. 91), signifique uma crítica ao capitalismo, mas, na verdade, trata-se de um alerta à

\footnotetext{
${ }^{9}$ A influência positivista no pensamento deweyano é sistemática: da noção de ordem social e de progresso industrial, como relação entre estática e dinâmica, tão cara a Comte (GIANNOT'TI, 1978; HENNING, 2009), a uma ética do progresso individual como base do progresso social, tão fortemente postulada por Weber (2004). 
forma pela qual está se dando o processo de trabalho, por meio do qual se impede a endosmose social (p. 90) e, portanto, a democracia liberal.

A finalidade dessa crítica à divisão técnica do trabalho, portanto, é corrigir desvios do processo produtivo, por meio dos quais, para ele, a democracia liberal se tornaria inviável. Na base dessa crítica há outra aproximação com o pensamento de outro positivista: Durkheim (1999, p. 01-09), para quem a divisão do trabalho, estreitamente vinculada à moral, é necessária por respeitar as aptidões individuais (distintivas), sincronizando-as para manter a coesão social (endosmose social para Dewey). O imperativo categórico dessa concepção é, para Durkheim (1999, p. 06): "Coloca-te em condições de cumprir proveitosamente uma função determinada"!

A eficiência cívica, por sua vez produto da eficiência industrial, consiste na capacidade de compartilhamento das necessidades e fazeres sociais, em "dar e receber da experiência comum", e que capacita o homem não só para julgar sensatamente, mas também para fazer leis e obedecê-las (DEWEY, 1979, p. 131). Assim, se a eficiência social é formação para o trabalho (eficiência industrial) e para a vida social (eficiência cívica), compete à educação prover os meios para que haja eficiência social (DEWEY, 1979, p. 105).

Finalmente, a cultura pessoal, terceira dimensão da concepção educacional, parte do pressuposto de que cultura e eficiência social não são conceitos opostos: àquela não é a lapidação desta, nas palavras de Dewey (1979, p. 132) "Quando se identifica o "natural" com esta bruteza, a cultura se opõe ao que chamamos desenvolvimento natural". Porém, quando as atividades (atos e operações) se identificam com "o espírito e a significação da atividade", a cultura se torna o "desenvolvimento completo da personalidade", cujo "resultado se identifica com o da verdadeira significação de eficiência social” (DEWEY, 1979, p. 132).

Ora, se compete à educação prover os meios para que haja eficiência social, a identidade entre esta e cultura pessoal (tanto para coibir as diferenças de oportunidades, quanto o resultado destas, a separação por classes), também, o será, tanto mais quanto o seja a base para a democracia liberal. De acordo com Dewey (1979, p. 133): [...] se a democracia tem significação moral e ideal, é porque se exige de todos uma retribuição social e porque se proporciona, a todos, oportunidade para o desenvolvimento de suas aptidões distintivas. O divórcio dos dois objetivos na educação é fatal à democracia [...].

Assim, tanto os princípios epistemológicos, quanto os políticos, adotados por Dewey, fazem com que fale sempre no público e no bem comum, como endosmose social para a democracia. A progressividade não se restringe ao desenvolvimento biológico, mas também ao social e, portanto, a educação não pode ficar restrita aos doze anos, como na proposta da Revolução Francesa; diferentemente, para ele, a educação deve ser progressiva a todas as idades ou etapas da formação. O contrário será fatal à democracia (liberal)!

Desse modo, a concepção educacional de Dewey compõe-se de desenvolvimento, biologicamente falando, vinculado à saúde fisiológica do corpo; de eficiência social, enquanto formação para o trabalho e formação cívica; e de formação cultural que, tendo por base as duas dimensões anteriores, constitui o desenvolvimento completo da personalidade que, numa sociedade democráticoliberal, todo cidadão teria direito.

A concepção educacional de Dewey constitui o paroxismo da concepção educacional da burguesia de 1789 e, mesmo assim, ele não foi uma unanimidade: criador da Laboratory School, a escola experimental da Universidade de Chicago (WESTBROOK, 2010, p. 22-29), de onde saiu demitido para trabalhar na Universidade de Columbia, onde ajudou a criar a Lincoln School, em 1917. Suas ideias e experiências pedagógicas desagradam tanto a conservadores liberais, quanto a liberais religiosos, mas exercem, progressivamente, grande influência no pensamento pedagógico mundial, inclusive no Brasil, por intermédio de Anísio Teixeira, que inaugura o pensamento educacional voltado para a educação integral.

A influência de Dewey sobre Anísio Teixeira é um fato consumado. Fato esse que, de acordo com Silva (2017, p. 22-23) precisa ser devidamente relativizado por duas razões: a primeira, em função de haver documento, sob a responsabilidade de Teixeira, a Lei n. 1.846, de 14 de agosto de 1925, do Governo do Estado da Bahia (BAHIA, 1925), pelo qual expressa a seguinte concepção de educação: "O Ensino Público no Estado da Bahia tem objectivo educar physica, moral e intelectualmente o individuo, 
tornando-o apto para a vida em sociedade" (BAHIA, 1925, p.177), que é ipsis litteris a mesma da Revolução Francesa; a segunda, porque Teixeira só veio a tomar conhecimento das ideias de Dewey, em 1927 e a conhecê-lo, em 1928. Logo, não é possível haver influência de Dewey sobre Teixeira em 1925.

A influência de Dewey sobre Teixeira, de acordo ainda com Silva (2017, p. 23), se faz notar, efetivamente, no Relatório de Gestão -1924/1928, ao governo bahiano, quando indica (TEIXEIRA, 1928, p. 08) como a escola primária deve ser:

Essa escola primaria deve ser, na forma da lei fundamental do ensino, sobretudo educativa, buscando exercitar nos meninos os habitos de observação e raciocinio, despertando-lhes o interesse pelos ideaes e conquistas da humanidade, ministrando-lhes noções rudimentares de literatura e historia patria, fazendo-os manejar a lingua portugueza como instrumento de pensamento e da expressão; guiando-lhes as actividades naturaes dos olhos e das mãos mediante formas adequadas de trabalhos praticos e manuaes; cuidando, finalmente, do seu desenvolvimento physico com exercicios e jogos organizados e conhecimento das regras elementares de hygiene, procurando sempre não esquecer a terra e o meio a que a escola deseja servir, utilizando-se o professor de todos os recursos para adaptar o ensino ás particularidades da região e do ambiente bahiano.

A citação supra expressa a influência de Dewey por meio de termos utilizados pelo americano: exercitar hábitos de "observação e raciocínio", desenvolver "actividades naturaes dos olhos e das mãos" dirigidas para os trabalhos práticos e manuais, ênfase no desenvolvimento físico e conhecimento das regras de higiene, termos esses que se tornam mais explícitos quando afirma que os institutos educativos devem "completar a educação elementar do bahiano, todos condicionados a uma nítida finalidade de "efficiencia social", finalidade que deve presidir a educação para uma democracia" (TEIXEIRA, 1928, p. 4).

A ênfase dada às atividades naturais dos olhos e das mãos com a finalidade de desenvolver habilidades práticas e manuais evidencia que às três dimensões educacionais expressas no documento de 1925, acrescenta-se, agora, a habilitação para o trabalho, prático e manual, portanto, para atividades subalternas.

A concepção de educação integral de Teixeira (1959, p. 79) está clara no discurso inaugural do Centro Educacional Carneiro Ribeiro, em 1950, quando assim se expressa:

E desejamos dar-lhe seu programa completo de leitura, aritmética e escrita, e mais ciências físicas
e sociais, e mais artes industriais, desenho, música, dança e educação física. Além disso,
desejamos que a escola eduque, forme hábitos, forme atitudes, cultive aspirações, prepare,
realmente, a criança para a sua civilização - esta civilização tão difícil por ser uma civilização
técnica e industrial e ainda mais difícil e complexa por estar em mutação permanente. E, além
disso, desejamos que a escola dê saúde e alimento à criança, visto não ser possível educá-la no
grau de desnutrição e abandono em que vive.

Nesse pequeno extrato do discurso de 1950 está expressa toda a concepção educacional de Teixeira, uma concepção que extrapola os limites de uma concepção convencional de educação que, até então, os governos burgueses ofereciam às classes trabalhadoras, mesmo a proposta por Dewey.

Aqui, embora não utilize o termo “integral”, a educação se propõe a uma formação completa, desde os suportes mais elementares, como saúde e alimentação, passando pela convencional instrução científica, física e industrial, chegando até a formação ética para uma sociedade democrática.

Com Teixeira, a educação brasileira chega ao paroxismo da política educacional liberal, tanto em concepção, quanto em realização. Excetuando-se políticas educacionais de governos, talvez Darcy Ribeiro, seja o único, após ele, que tenha pensado e realizado uma obra educacional. O Quadro II é uma tentativa didática de sintetizar as dimensões pedagógicas da concepção liberal de educação, aqui, expostas.

A concepção liberal de educação, portanto, se alicerça numa base sólida composta por educação intelectual, educação física e educação moral, tal como se encontra em Condorcet, Lepelletier, Dewey e Teixeira, pré e imediatamente pós-Dewey. A formação para o trabalho, embora não faça parte da trilogia (intelectual, física e moral), se encontra esparsamente detalhada, ora no âmbito da educação física, ora no âmbito da moral, ora, ainda, na interface das duas dimensões, mas sempre direcionada ao trabalho subalterno. 
Quadro II - Síntese das dimensões pedagógicas da concepção liberal de educação

\begin{tabular}{|l|l|l|l|l|}
\hline \multicolumn{1}{|c|}{ Autor } & \multicolumn{3}{|c|}{ Dimensões pedagógicas da concepção educacional } \\
\hline Condorcet & $\begin{array}{l}\text { Educação } \\
\text { intelectual }\end{array}$ & Educação física & $\begin{array}{l}\text { Habilidades para } \\
\text { o trabalho }\end{array}$ & Educação moral \\
\hline Lepelletier & $\begin{array}{l}\text { Educação } \\
\text { intelectual }\end{array}$ & Educação física & Trabalho manual & Educação moral \\
\hline Dewey & $\begin{array}{l}\text { Educação para a } \\
\text { eficiência social e } \\
\text { cultura pessoal }\end{array}$ & $\begin{array}{l}\text { Educação do corpo } \\
\text { - desenvolvimento } \\
\text { biológico }\end{array}$ & $\begin{array}{l}\text { Ocupações com } \\
\text { eficiência social - } \\
\text { Endosmose }\end{array}$ & $\begin{array}{l}\text { Regras sociais e } \\
\text { eficiência cívica. } \\
\text { Democracia liberal }\end{array}$ \\
\hline $\begin{array}{l}\text { Teixeira } \\
\text { pré-Dewey }\end{array}$ & $\begin{array}{l}\text { Educação } \\
\text { intelectual }\end{array}$ & Educação física & - & Educação moral \\
\hline $\begin{array}{l}\text { Teixeira } \\
\text { pós-Dewey }\end{array}$ & $\begin{array}{l}\text { Educação } \\
\text { intelectual }\end{array}$ & Educação física & $\begin{array}{l}\text { Trabalho prático } \\
\text { emanual }\end{array}$ & Educação moral \\
\hline $\begin{array}{l}\text { Teixeira } \\
\text { Educação } \\
\text { Integral }\end{array}$ & $\begin{array}{l}\text { Educação } \\
\text { intelectual } \\
\text { Instrução (ciências) } \\
\text { Escola-Classe }\end{array}$ & $\begin{array}{l}\text { Educação física, } \\
\text { saúde, higiene e } \\
\text { alimentação } \\
\text { Escola-Parque }\end{array}$ & $\begin{array}{l}\text { Artes e técnicas } \\
\text { industriais, } \\
\text { música, dança } \\
\text { Escola-Parque }\end{array}$ & $\begin{array}{l}\text { Democracia liberal: } \\
\text { Atitudes, hábitos, } \\
\text { aspirações } \\
\text { Escola-Parque }\end{array}$ \\
\hline
\end{tabular}

Fonte: Elaborado pelos autores.

As dimensões intelectual, física e moral da concepção liberal coincidem com a concepção anarquista, mas somente na forma, a base epistemológica de onde parte, os processos educativos pelos quais se realizam, os fins aos quais almejam são totalmente opostos. Anarquistas e marxistas coincidem em grande parte, mas a base epistemológica, os processos e os fins da concepção marxista de educação ultrapassam a condição de oposição à concepção burguesas: são antagônicos em relação a esta!

Para os marxistas, a dimensão do trabalho deixa de ser uma dimensão implícita, para se tornar não só uma das três dimensões da trilogia, mas também a dimensão mais importante das três, base da condição humana.

Por fim, três observações em relação a Anísio Teixeira: primeira, não há dúvida sobre a influência exercida sobre ele por Dewey, mas, antes deste, a concepção adotada por Teixeira coincide com a da Revolução Francesa, portanto, já há uma base anterior que não decorre de Dewey. Segunda, a influência mais forte deste se dá no período imediatamente posterior, por ocasião da experiência dele na Diretoria da Instrução Pública do Distrito Federal, após o curso que faz com Dewey, na Universidade de Columbia, em 1928.

Terceira, a concepção educacional genuinamente de Teixeira emerge com o Centro Popular de Educação, como era chamado por ele o Centro Educacional Carneiro Ribeiro, escola inaugurada em 1950, em Salvador, e se consolida com a Escola-Parque 308 Sul, inaugurada, em 1960, em Brasília. Nesta concepção, Teixeira parece perceber o recuo pedagógico da concepção educacional liberal no sentido de não oferecer uma escola igual para todos, mesmo em se tratando de sistema público, o sistema oferecido às classes subalternas. A concepção dele concretizada nas duas escolas, de Salvador e Brasília, são a prova de que ele pretendia resgatar a noção inicial, em particular Condorcet, da Revolução Francesa de uma escola universal para todos, pela qual as múltiplas faculdades humanas pudessem ser trabalhadas: a concepção de educação liberal convencional dá lugar à educação liberal integral. Mas, tal como acontecera a Dewey, em Chicago, essa concepção educacional não foi aceita nem por liberais conservadores, nem por liberais católicos.

De fato, não fosse sua convicção liberal-democrática, sua luta por uma escola que garantisse a formação mais completa possível para a vida numa sociedade a caminho da industrialização e da democracia liberal, poderia ser confundida com a perspectiva socialista, mas isto ontem, como hoje, é inadmissível. 


\section{CONSIDERAÇÕES FINAIS: DA CONCEPÇÃO AO CONCEITO DE EDUCAÇÃO INTEGRAL}

A falta de rigor conceitual, nas últimas décadas, tem levado a uma confusão entre concepção, conceito e definição de conceito. Por essa razão, antes de ir às definições de concepção e conceito, pensase importante, esclarecer tais termos.

No campo da epistemologia, concepção é a visão que se tem de algo (mundo, homem, sociedade, etc.), uma visão em processo, em busca de clareza sobre alguma coisa. Nesse sentido, a concepção é sempre uma visão inacabada das propriedades, que constituem aquilo que se quer conhecer e, portanto, definir. É por meio da definição que se transforma a concepção em conceito.

O conceito, produto da concepção, é representado por um termo que apresenta duas propriedades: o significante, invariável e atemporal; e o significado, temporal e variável, conforme o momento histórico, a área de conhecimento, a profundidade científica alcançada, a concepção filosófica, a vinculação ideológica, etc. Portanto, o significado é determinado pela definição do conceito.

Por isso, o mesmo conceito, educação por exemplo, tem diversas, diferentes e, não raramente, antagônicas definições, por atender as suas determinações concretas (momento histórico, desenvolvimento científico, interesses de classe, etc.). Com base nestes pressupostos, pode-se entender a concepção como processo, o conceito como produto e a definição como atualização histórica do conceito.

Nesse sentido, as concepções de Condorcet e Lepelletier engendram as mesmas propriedades, mas as definições do conceito apresentam a mais significativa diferença para a história das políticas educacionais liberais. Em Condorcet, pensa-se, ainda, numa educação universal, um sistema único para todos; em Lepelletier, a partir dos 12 anos, a educação se torna dual, reproduzindo o sistema de classes da sociedade: a educação física e moral caminha no sentido do trabalho manual e, portanto, para as classes subalternas; a educação intelectual, para as funções executivas e, portanto, para as classes dominantes. A partir de então, todo sistema educacional liberal será operacionalizado dessa forma, como sistema dual: educação pública para as classes subalternas e privada para as classes dominantes, ambas hierarquicamente distribuídas segundo o lugar e o papel desempenhado por elas na estrutura social.

Do lado socialista, o anarquista Proudhon é o primeiro a perceber a manobra educacional burguesa, por isso levanta a bandeira da educação unitária e postula educação integral de forma a conciliar a divisão parcelar do trabalho com o desenvolvimento das faculdades humanas (também para ele: intelectual, física e moral).

Duas grandes contribuições de Proudhon para a concepção proletária de educação são a crítica à divisão do trabalho, relacionando-a a idiotização humana, e a proposta da educação integral como alternativa para a humanização dos trabalhadores.

A crítica à divisão do trabalho, reproduzida no âmbito educacional pelos sistemas educacionais, crítica essa assumida por Robin e levada ao extremo por Bakunin, todavia, não será suficiente para fazê-los perceber de que partiam e se fundamentavam sobre os mesmos fundamentos da concepção liberal, motivo pelo qual, pelo menos em Proudhon e Robin, a proposta de educação integral tinha por pressuposto a aquiescência e a boa vontade dos sistemas liberais de educação. Daí a luta para que os liberais cumprissem suas promessas de igualdade de direito, formalmente consolidada pelas leis.

Marx inverte essa lógica. Admite partir, mas não se fundamentar. Admitindo a importância da educação intelectual e o desenvolvimento físico, substitui a moral pelo trabalho. Não pela concepção liberal de trabalho, já criticada por Proudhon, mas pelo trabalho politécnico, única forma, desde o processo produtivo, de reunificar o desenvolvimento das faculdades humanas e, nesse sentido, muito mais do que um dos fatores, o trabalho politécnico se torna o fundamento do desenvolvimento humano, na sociedade que tem por base a divisão técnica e social do trabalho.

Embora Marx nunca tenha utilizado o termo educação integral, depreende-se da crítica à divisão do trabalho capitalista, força motriz da alienação, e da proposta educacional, com vistas à humanização e emancipação dos trabalhadores, que se trata de educação integral (MARX, 1987, p. 177179; MACIEL, 2018). 
Nesse sentido, pelo lado socialista, toda proposta de educação integral deve ter por fundamento a crítica da divisão social e técnica do trabalho e visar ao desenvolvimento de todas as potencialidades humanas, o desenvolvimento integral do ser humano.

No Brasil, a proposta de educação integral chega por meio de Teixeira que, também, jamais utilizou o termo educação integral (CAVALIERE, 2010, p. 250), mas sua proposta aponta para o desenvolvimento das múltiplas potencialidades humanas (SILVA, 2017, p. 22-31).

Como a concepção de Teixeira, segundo maioria absoluta de autores, está associada à de Dewey, foi necessário, aqui, rever essa relação que, como se viu, tem pontos de aproximação e de distanciamento: aproximação no que diz respeito a concepção clássica de educação baseada no desenvolvimento intelectual, físico e moral, na crítica restrita à divisão técnica do trabalho, que dificultaria o exercício da democracia (liberal) e no ideal democrático de sociedade; distanciamento no que diz respeito a forma como se deve enfrentar as restrições da sociedade capitalista: Dewey envereda por uma escola experimental integrada ao sistema educacional capitalista; Teixeira, por uma escola indiretamente integrada ao sistema, sob a forma de educação integral para as classes "menos favorecidas".

Desse modo, tem-se, na origem, a educação como desenvolvimento universal das faculdades intelectuais, físicas e morais do ser humano (Condorcet), desenvolvimento parcial das mesmas faculdades (Lepelletier), desenvolvimento das mesmas faculdades humanas orientado para a sociedade industrial e democrático-liberal (Dewey) e o mesmo desenvolvimento voltado para uma sociedade democráticoliberal e para o mundo do trabalho subalterno (Teixeira).

Do lado socialista, os anarquistas, também, se baseiam nas faculdades intelectuais, físicas e morais do ser humano, mas desfecham severa crítica à divisão do trabalho, evidenciando as implicações dessa divisão na humanidade do ser humano. Por esta razão, propõem a educação integral, como alternativa para reverter esses efeitos, porém, apelando para o cumprimento das promessas liberais, pelas quais todos teriam igualdade de direito à educação.

Marx, de todos, é o único que foge ao padrão "intelectual, físico, moral". Admitindo as faculdades intelectual e física, substitui a moral pelo trabalho politécnico, mas de tal modo que este se tornaria fundamento integrado (diria ele, combinado) às demais faculdades. Para Marx, não se trata de apelar para os direitos formais propostos pela burguesia, com o que se incorreria no equívoco dos socialistas utópicos, trata-se de impor, pela luta política, essa proposta que elevará a educação da classe operária a níveis superiores aos da burguesia.

Em síntese: toda educação, que se queira integral, deve visar ao desenvolvimento das múltiplas faculdades humanas e a única forma de alcançá-la é proporcionando processos educativos, que abranjam as ciências, as artes, os esportes, (no caso da educação pública, com nutrição e saúde), todos integrados aos processos produtivos do mundo do trabalho e da tecnologia, em período escolar integral.

Com isso, pode-se chegar às seguintes definições de educação e de educação integral, via escola pública do Estado liberal: educação, mesmo em período escolar integral, é um processo de desenvolvimento parcial das faculdades humanas, voltado para as funções subalternas da sociedade capitalista, na perspectiva da manutenção do status quo. Educação integral liberal é um processo de desenvolvimento seletivo das múltiplas faculdades humanas, para as atividades subalternas e subalternas médias, na perspectiva da manutenção do status quo. Educação integral politécnica é um processo de desenvolvimento das múltiplas faculdades humanas voltado para a compreensão integrada dos processos produtivos e, portanto, para o trabalho emancipatório, numa perspectiva de transformação das condições sociais existentes. Portanto, três definições, três modalidades de educação integral.

\section{REFERÊNCIAS}

BAHIA. LEI n. 1.846, de 14 de agosto de 1925. Dispõe sobre a Reforma da Instrução Pública. Disponível em: https://repositorio.ufsc.br/bitstream/handle/123456789/134871/15\%20\%20Lei $\% 20 \mathrm{~N} . \% 201.846 \% 2$ c $\% 20 \mathrm{de} \% 2014 \% 20 \mathrm{de} \% 20$ Agosto $\% 20 \mathrm{de} \% 201925$.pdf?sequence=1\&isAllowed $=$ y. Acesso em: 15 maio 2016.

BAKUNIN, M. A instrução integral. Tradução Luiz Roberto Malta. São Paulo: Imaginário, 2003. 
BARRERA, T. G. da S. O movimento brasileiro de renovação educacional no início do século XXI. 274 f. 2016. Tese (Doutorado em Educação) - Faculdade de Educação, USP, São Paulo, 2016.

CAVAliere, A. M. Anísio Teixeira e a educação integral. Paideia, Ribeirão Preto, SP, v. 20, n. 46, p. 249-259, maio/ago. 2010.

CONDORCET, J. N. C. Rapport et projet de décret sur l'organisation générale de l'instruction publique, présentés à l'Assemblée Nationale au nom du Comité de Instruction Publique, par M. Condorcet, Député du Départment du Paris: Les 20 \& 21 Avril 1792. Disponível em: https://gallica.bnf.fr/ark:/12148/bpt6k3044154t.texteImage. Com ortografia atualizada em: http://www.assemblee-nationale.fr/histoire/7ed.asp. Acesso em: 16 jun. 2017.

DALBOSCO, C. A. Princípios filosóficos e pedagógicos da educação natural em Rousseau: uma investigação sobre o segundo livro do Émile. Educação \& Sociedade, Campinas, SP, v. 33, n. 121, p. 1117-1131, out./dez. 2012.

DEWEY, J. Democracia e educação: introdução à filosofia da educação. Tradução Godofredo Rangel. 4. ed. São Paulo: Nacional, 1979.

DURKHEIM, É. Da divisão do trabalho social. Tradução: Eduardo Brandão. 2. ed. São Paulo: Martins Fontes, 1999.

ENGELS, F. A situação da classe trabalhadora na Inglaterra: segundo as observações do autor e fontes autênticas. Tradução: B. A. Schumann. São Paulo: Boi Tempo, 2008.

GADOTTI, M. Educação integral no Brasil: inovações em processo. São Paulo: Editora e Livraria Instituto Paulo Freire, 2009.

GIANNOTTI, J. A. Comte: vida e obra. In: COMTE, A. Comte (1798-1857). Tradução: José Arthur Giannotti e Miguel Lemos. São Paulo: Abril Cultural e Industrial, 1978. (Coleção Os Pensadores). páginas

HENNING, L. M. P. Estudo sobre as possíveis ligações de Dewey à tradição comteana: respingos na filosofia e educação brasileira. 14 p. Anais da 32a. Reunião Anual da ANPED. Caxambu, MG. 2009. Disponível em: http://32reuniao.anped.org.br/arquivos/trabalhos/GT17-5869--Int.pdf. Acesso em: 26 mar. 2018.

HUSSON, J. Paul Robin - éducateur. Cannes, França: Éditions de l'École Moderne Française, 1949. (Brochures d'Education Nouvelle Populaire $N^{\circ} 44$ - mars, 1949). Disponível em: https://www.icempedagogie-freinet.org/node/11167. Acesso em: 05 jun. 2017.

HOBSBAWN, E. J. A era do capital - 1848/1875. Tradução: Luciano Costa Neto. 3. ed. Rio de Janeiro: Paz e Terra, 1982.

LEPELLETIER, M. Plan d'Éducation Nationale: présenté a la Convention par Maximilen Robespierre, au nom de la Comission d'Instruction Publique, Le 13 Juillet 1793. Disponível em: http://gallica.bnf.fr/ark:/12148/bpt6k48991b/f5.image. Com ortografia atualizada em https://www.samuelhuet.com/fr/paid/43-melanges/755-plan-deducation-nationale1.html: Acesso em: 16 jun. 2017.

MACIEL, A. C. A incansável luta da escola pública contra o diabo às portas do inferno.

Educamazônia. Manaus, ano 6, v. XI, n. 2, p. 74-106, jul./dez. 2013.

Marx e a politecnia, ou: do princípio educativo ao princípio pedagógico. Exitus, Santarém, PA, v. 8, n. 2, p. 85-110, maio/ago. 2018. 2019.

Educação integral: ruídos analógicos em tempos digitais. Porto Velho: CIEPES/UNIR,

MACIEL, A. C.; BRAGA, R. M. Politecnia e emancipação humana: uma metodologia para a formação histórico-crítica na universidade. In: AMARAL, Nair G. M.; BRASILEIRO, Tania S. A. (Orgs.). 
Formação docente e estratégias de integração universidade/escola nos cursos de licenciatura. São Carlos - SP: Pedro \& João; Porto Velho: EDUFRO, 2008. p. 203-217.

MACIEL, A. C.; JACOMELI, M. R. M.; BRASILEIRO, T. S. A. Fundamentos da educação integral politécnica: da teoria à prática. Educação \& Sociedade. Campinas, SP, v. 38, n. 139, p. 473-488, abr./jun., 2017.

MARX, K. O capital (crítica da economia política). Livro 1: o processo de produção do capital, v. 1. Rio de Janeiro: Civilização Brasileira, 1980.

Instructions pour les délégués du Conseil central provisoire à propos de diverses questions. In: MARX, K.; ENGELS, F. Critique de l'éducation et de l'enseignement: [Une anthologie de MarxEngels sur l'éducation, l'enseignement et la formation professionnelle]. Introduction, traduction et notes de Roger Dangeville. Paris: François Maspero, 1976. Disponível em:

https://inventin.lautre.net/livres/Marx-critique-de-l-education.pdf. Acesso em: 18 abr. 2017. p. $177-$ 179.

Instructions for the delegates of the Provisional General Council: the different questions. The International Workingmen's Association, 1866. Publicação em 1996. Disponível em: https://www.marxists.org/archive/marx/works/1866/08/instructions.htm. Acesso em: 18 abr. 2017.

. Instruções aos delegados do Conselho Central Provisório, AIT, 1868. In: MARX, K.;

ENGELS, F. Textos sobre educação e ensino. São Paulo: Moraes, 1983a. p 59-61.

. Exposição nas sessões dos dias 10 e 17 de agosto de 1869 no Conselho Geral da AIT. In: MARX, K; ENGELS, F. Textos sobre educação e ensino. São Paulo: Moraes, 1983a. p. 96-98.

. Contribuição à crítica da economia política. 2. ed. São Paulo: Martins Fontes, 1983b.

Crítica del programa de Ghota. Moscú: Progreso, 1979.

Manuscritos econômico-filosóficos e outros textos escolhidos. São Paulo: Nova Abril, 1987. (Coleção Os Pensadores).

MARX, K; ENGELS, F. Manifesto do partido comunista. Organização e introdução de Osvaldo Coggiola. São Paulo: Boitempo, 1998.

MOREL, J. C. O. Introdução. In: PROUDHON, P-J. Sistemas das contradições econômicas ou filosofia da miséria. t. 1. São Paulo: Ícone, 2003. p. 7-32.

NETTO, J. P. Introdução ao estudo do método de Marx. São Paulo: Expressão Popular, 2011.

NEILL, A. S. Liberdade sem medo (Summerhill): radical transformação na teoria e na prática da educação. Tradução de Nair Lacerda. 9. ed. São Paulo: IBRASA, 1970.

OLIVEIRA, J. de A.; SILVA, Y. F. de. As concepções educacionais e pedagógicas de Locke e a educação profissional. Saberes, Natal, v. 19, n. 2, p. 188-205, ago. 2018.

OMB. ORGANIZAÇÃO MONTESSORI DO BRASIL. Movimento Montessori do Brasil.

Disponível em: http://omb.org.br/educacao-montessori/a-classe-agrupada. Acesso em: 8 ago. 2020.

PROUDHON, P-J. Sistemas das contradições econômicas ou filosofia da miséria. t. 1. São Paulo: Ícone, 2003.

Sistemas das contradições econômicas ou filosofia da miséria. t. 2. São Paulo: Escala, 2007.

ROBIN, P. L'Éducation intégrale, culture harmonique de toutes les facultés physiques, intellectuelles et affectives: sommaire de conférences. Paris: Impr. de La Régénération humaine, 1902.

ROUSSEAU, J-J. Do contrato social. Edição Ridendo Castigat Mores. Tr 
adução Rolando Roque da Silva. Amsterdam, 1762. Fonte digital: www.jahr.org. Disponível em: http://www.ebooksbrasil.org/adobeebook/contratosocial.pdf. Acesso em: 10 ago. 2020.

SANTOS, L. E dos. A educação libertária e o extraordinário: traços de uma pedagogia (r)evolucionária. 218 f. Tese (Doutorado em Educação) - Faculdade de Educação, USP, São Paulo, 2014.

SAVIANI, D. Escola e democracia. Edição comemorativa. Campinas, SP: Autores Associados, 2008. 2003.

Pedagogia histórico-crítica: primeiras aproximações. 7. ed., São Paulo: Autores Associados,

As concepções pedagógicas na história da educação brasileira. Campinas, SP: UNICAMP, Projeto "20 anos do HISTEDBR”, 2005.

SBRANA, R. A. A filosofia educacional de John Dewey e Jean-Jacques Rousseau: um estudo comparativo por meio da análise retórica. 228f. Tese (Doutorado em Educação Escolar) Universidade Estadual de São Paulo, Campus Araraquara, Araraquara, SP, 2018.

SILVA, A. G. S.; MIORONZA, C. Notas de rodapé 59. In: PROUDHON, P-J. Sistemas das contradições econômicas ou filosofia da miséria. t. 2. São Paulo: Escala, 2007. p. 266.

SILVA, C. A. O sistema público de educação de tempo integral em Manaus e as possibilidades da educação integral politécnica. 204 f. Dissertação (Mestrado em Educação) - Universidade Federal de Rondônia, Porto Velho, RO, 2017.

SNYDERS, G. Escola, classes e luta de classes. Tradução: Leila Prado. São Paulo: Centauro, 2005.

SPENCER, H. Educação intelectual, moral e física. Prefácio de Ricardo Jorge, 1881. Disponível em: http://www.filosofia.com.br/figuras/livros_inteiros/266.txt. Acesso em:8 ago. 2020.

TAMBARA, E. A. C.; ARRIADA, E. John Locke: alguns problemas referentes à educação do pobre. História da Educação. Porto Alegre, v. 21, n. 52, p. 363-378, maio/ago. 2017.

TEIXEIRA, A. Relatório: apresentado ao Ex. Sr. Cons. Bráulio Xavier da Silva Pereira, Secretário do Interior, Justiça e Instrução Pública, pelo Diretor Geral da Instrução Pública, para ser encaminhado ao governador do Estado da Bahia. Salvador: Imprensa Oficial do Estado, 1928. Disponível em: http://www.bvanisioteixeira.ufba.br/artigos/summario.htmlhttp://www.bvanisioteixeira.ufba.br/artig os/summario.html. Acesso em: 1 jul. 2017.

Centro Educacional Carneiro Ribeiro. Revista Brasileira de Estudos Pedagógicos. Rio de Janeiro, v. 31, n. 73, p.78-84, jan./mar. 1959.

THOMPSON, E. P. A formação da classe operária inglesa: A árvore da liberdade, I. Tradução: Denise Bottmann. 4. ed. Rio de Janeiro: Paz e Terra, 2004.

VIOLET, M. L'Éducation intégrale. Pedagogies alternatives. Les actes de lecture. n. 112, dez. 2010.

VIOLET, R. Régénétion hamaine et éducation libertaire: L’influence du néo-malthusianisme français sur les expériences pédagogiques libertaires avant 1914. 2002. Dissertação (maittrise em Histoire Contemporaine) - Université Marc Bloch (Strasbourg II), Strasbourg, França, 2002. Disponível em: http://mapage.noos.fr/renaudviolet/chap2.htm. Acesso em 12 jun. 2017.

WEBER, M. A ética protestante e o "espírito” do capitalismo. Tradução: José Marcos Mariani de Macedo. São Paulo: Companhia das Letras, 2004.

WESTBROOK, R. B. John Dewey. In: WESTBROOK, R. B.; TEIXEIRA, A. John Dewey. Tradução e organização: José Eustáquio Romão e Verone Lane Rodrigues. Recife: Fundação Joaquim Nabuco/Massangana, 2010. p. 11-32. 
Submetido: $04 / 04 / 2020$

Aprovado: $25 / 08 / 2020$ 